\title{
Home Is Where the Female Is: Analysing the Geography of Gender Inequalities and the Home
}

\author{
By Janine Isaac
}

\begin{abstract}
Discourses on the home as a physicality often recount on romantic or nostalgic notions such as safety, comfort, and identity. Home as a defined boundary from the public realm and as a private space can be conceptualised as a gendered landscape, in which women are confined to roles involving reproductive and domestic labor. Thus, in a paradoxical sense, although home is socially constructed to fit ideals and create a space of material safety, it can also create a geography of difference in terms of women and the systemic barriers that can lead to violence against women, such as domestic or familial violence. This paper discusses the geography of the home and its physical and social attributes as it intersects with gender inequalities. Moreover, an intersectional and focused analysis on how domestic violence can occur because of gendered perceptions in the home is provided. This introductory research paper examines existing literature and can add to the limited research in domestic violence against women. Thus, the paper may be used to inform future housing policy such that a more comprehensive approach which includes domestic violence perspectives are considered.
\end{abstract}

\section{Introduction}

Discourses on the home as a physicality often recount on romantic or nostalgic notions as a structure that houses both material and symbolic items such as safety, comfort, and identity (Mallett, 2004). Home is a defined spatial boundary from the public realm and thus provides a private space for individuals to dwell in and seek refuge. As such, the home can be also conceptualised as a gendered landscape, in which women are confined to roles involving reproductive and domestic labor. Having said that, while home is socially constructed to fit ideals and create a space of material safety, it can also create a geography of difference regarding women and the systemic barriers that can lead to violence against women. As Wardhaugh (1999) explains, in homes where women are victimised, women begin to adopt an identity as individuals who are 'homeless at home', thus reifying the phenomena of homelessness and domestic violence as gendered and ripe with inequalities.

This linkage between gender inequalities and the home conceptualises an unjust boundary in which negative stigmas around women continue to permeate throughout society. Moreover, the home allows boundaries to occur in terms of the victimisation of women behind closed doors. This paper will discuss the physical and social attributes of the home and how they intersect with gender inequalities to create a geography of difference for women. In order to conceptualise this geography of difference, a contextual analysis on gendered perceptions of home and how it can lead to barriers for women will be provided. Finally, a focused analysis on how the victimisation of women and domestic violence can occur as a result of the gendered perceptions of the home will be discussed. 


\section{Home as a Geography of Difference}

\section{Boundaries Within the Intersection of Homelessness, Gender, and Self-Identity}

In existing literature, the home is established as a place that separates the inside or private space from the outside or public realm, creating a defined microcosm of security and liberation from fear and crime. Easthope (2004) explains that home establishes an extension of self-identity and provides a sense of familiarity and refuge. Home can also be attributed to an individual's wellbeing since shelter is a basic human right. On the contrary, economic consequences such as job insecurity can have negative impacts and remove home as a space of refuge and necessity, rendering individuals homeless. This absence of home and lack of a basic human right creates an area of negative self-identity where individuals become vulnerable to adverse outcomes such as chronic disease or substance use (Shelton, Taylor, Bonner, \& van den Bree, 2009). That said, applying a gender lens to this phenomenon provides insight on how home or the absence of it - can create a gendered landscape of barriers through the concept of self-identity. In other words, in order to further our understanding on home as a gendered geography of difference, an examination of homelessness and how it constructs a negative stigma towards women is needed.

Homelessness becomes a geography of difference as it reinforces spatial and social barriers between the homeless and sheltered thus promoting an exclusionary environment of clashing identities - the haves and the havenots (Easthope, 2004). When applying a gender lens to homelessness, male demographics are often emphasised in statistics due to women's hidden homelessness, where rather than seeking a space at a shelter, women choose to temporarily live with family, friends, or other places (Klodawsky, 2006; Rodrigue, 2016). In their 2017 report, the Canadian Mortgage and Housing Corporation (CMHC) explains that women's hidden homelessness could be due to a woman's increased fear of external violence thus, providing insight on why women choose alternative temporary housing over shelters. In addition to women's hidden homelessness and its associated factors, a negative stigma can be attached to homeless women. This can be conceptualised in terms of the female identity such that it does not coincide with fixed gender ideals in which women are expected to maintain principles associated with femininity such as the attachment to home and maintaining this boundary through nurturance and other domestic duties (Wardaugh, 1999).

If another layer such as domestic violence was applied to this conceptualisation, the socially constructed female identity, bound by systemic patriarchal ideals, creates a cycle of vulnerability in terms of economic instability, susceptibility to further violence within the public realm, and an increased fear of no accommodation or atcapacity women's shelters (Meyer, 2016; CMHC, 2017). These factors leave no other choice for a woman but to return to an abuser (Meyer, 2016). Consequently, an unjust boundary is created since homelessness as a spatial boundary can further delineate gender inequalities in society. As this section examined the absence of home and the gender inequalities associated with this concept, the following will further this constructed identity and conceptualise the gendered divisions within home as a structure or physical boundary.

\section{Home as a Spatial Boundary and its Relationship with Design and Gender Ideals}

Since 1950, the post-war consumerist ideology fuelled the suburban ideal, putting the focus on women as major consumers (Madigan \& Munro, 1991). Consequently, in terms of spatial design, the physical dwelling is subject to home designs that reflect a gendered spatial organisation to which women are linked to areas relevant to their assumed role within the household (Mallett, 2004). The social constructs associated with this timeline create stereotypes in which women are consigned to, not just the home itself, but rather, a specific space within the home - the kitchen. Because 
of this historical notion, an analysis on the discourse of the kitchen as a gendered space is needed to understand the relationship between design, gender ideals, and how these coincide to create unjust boundaries within the home.

Madigan and Munro (1991) suggest that since the suburban ideal (which will be further expanded in the next section) was geared toward women, purchases and other design choices emphasised their identities. During this period, the public realm became more attributed to crime and threats; thus, the lack of desire to venture this area increased specifically for women (Tognoli, 1980). The kitchen then became a space where stereotypes reinforced women to the concept of domesticity such that central design defined the conventional homemaker/ housewife role (Madigan \& Munro, 1991; Blunt, 2005). Consequently, women are expected to "mak[e] a home" through their choices of furnishings and design as per their expected roles, which eventually confine them to the home (Bowlby, Gregory, \& McKie, 1997; Blunt, 2005).

The spatial notions discussed in this section provide another dimension regarding the geographies of the home as they intersect with social relations between other household members. These linked notions reify the gendered invisible boundaries with individuals and thus, create clashing identities. Since assigning gender roles to one's identity becomes systemic, a further examination on how these roles create labor divisions within the home is needed to give a comprehensive analysis on the geographies of the home.

\section{Gendered Labor Divisions Within the Home}

In a physical context, the home is often attributed to the traditional idea of suburbia in which the concept of family structure is built on the assumption of a heterosexual couple with dependents - the nuclear family (Frank, 2008). Consequently, assumed gender roles emerge from these social perceptions of home and are deeply rooted in patriarchal ideologies such that females are linked to the idea of domesticity and the private sphere (Mallett, 2004; Frank, 2008). In this case, women are consigned to childminding and engaging in unpaid labour, such as maintaining the house and cooking meals for their family (Bowlby et al., 1997). These ideals produce an othering effect such that an emphasised femininity is experienced by wives and daughters, linking their identities strictly to this concept. Female individuals are merely objectified without value as they are not working bodies in the public realm and thus, become static entities of the home (Wardhaugh, 1999).

As this conceptualisation of traditional suburbia and domesticity add to the gendered landscape of home, the negative stigma against homeless women mentioned in the previous section becomes perpetuated due to this socially constructed ideal. Furthermore, home as a spatial boundary in this sense strengthens the idea of exclusionary landscapes, as the private/public dichotomy is more clearly delineated through traditional suburban ideals. Expectations within the home may become increased above standards such that if a woman fails to "mak[e] a home" fit these expectations, the woman could become subject to domestic violence (Wardaugh, 1999; Bowlby et al., 1997). The next section outlines this idea further by focusing on how domestic violence can result due to unjust boundaries created by the home as a geography of difference.

\section{Victimisation of Women Within the} Home

As mentioned above, the home is socially constructed as a space of safety but can create spatially divided gendered landscapes due to systemic barriers. For example, if a woman feels trapped in the confines of the physical dwelling by doing relentless unpaid labor, she may also feel trapped in the confines of her social relationships (Wardaugh, 1999; Warrington, 2001). This can mean a homogenous routine lifestyle where a woman may interchange her roles between 'homemaker' and 'party host' repeatedly. On the contrary, the city streets or public realm remain a male-dominated space and add to 
the landscape of fear for women, which may make women choose to stay at home (Hille, 1999). By adding domestic violence as another dimension to the geographies of home, the social constraints intersect with the spatial constraints home creates an uneven distribution of power and control, exercised through violence, that paradoxically confines an individual to the home due to fear of the outside (Wardaugh, 1999; Hille, 1999; Warrington, 2001). As Warrington (2001) suggests, women experiencing domestic violence become marginalised both socially and spatially as they "fall short of the home ideal" and thus become 'homeless-at-home' (p.371).

In terms of domestic violence and battered women, boundaries associated with gender inequalities and space become clearly demarcated as women are marginalised within their homes by outside societal stigmas, and an increasing difficulty to access aids safely (Warrington, 2001). To explain further, women experiencing domestic violence are often treated like the Other by society and may be blamed as the instigator for their own beatings (Alberta Council of Women's Shelters, 2012). They can also be deemed as a "home-wrecker" (in a different sense of the word) if they break up the family dynamic by leaving (Warrington, 2001). Consequently, these attributes continue to perpetuate viewing women in domestic violence situations as the Other and creates a culture of fear and exclusion.

Women fleeing abuse may often resort to homelessness or at-capacity women's shelters (Wardhaugh, 1999). On the contrary, women choosing to abide by systemic ideals to avoid being ostracised and treated as the Other may stay in their abusive relationship. In many cases, if a woman stays in her abusive relationship, it can often lead to murder as the violence escalates over time and thus, contradicts the idea of home as a place of refuge and safety (Government of Alberta, 2012). Conversely, the absence of home creates a gendered landscape that can become problematic for women in terms of the stigmatisation of women's homelessness and society's continual attachment to patriarchal ideals. Women become assigned with this perception of being associated with the home, both spatially and socially. Consequently, domestic violence situations emphasise the idea of unjust boundaries created as a result of the home's geography of difference.

\section{Conclusion}

For most, home is a place of refuge and safety. However, when the geographies of home are intersected with gender, the home can become a place ridden with gender inequalities that can lead to the victimisation of women within the home. This paper identified factors that create unjust barriers due to these gender inequalities within the home. In order to provide a comprehensive analysis, investigating the absence of a home provided insight on how barriers can be created for women in terms of societal stigma and how these factors can support a feminised identity attached to the home. Women's homelessness is generally hidden and is often trivialised as their identity is attached to a gendered landscape - the home. As social constructs intermingle with spatial and physical divisions, the concept of home becomes understood as a dynamic landscape that can potentially victimise women. This social constraint within a constricted spatial structure that is deeply rooted in patriarchal ideals identifies an unjust boundary that can widen the gender inequality gap for women and create further social problems for women and their relationship with spatial structures, space, and place.

As such, future research should investigate the relation between domestic violence and geography as this area does not have extensive existing research and has yet to be explored. In this case, analysing how domestic violence intersects with geography challenges the concept of home as a haven and gives rise to discourses on the geographies of fear. Consequently, this research can be used to inform future housing policy such that domestic violence perspectives are considered for a more comprehensive approach and analysis. 


\section{References}

Alberta Council of Women's Shelters. (2012). Types of abuse. Retrieved from https:// acws.ca/types-of-abuse

Blunt, A. (2005). Cultural geography: cultural geographies of home. Progress in Human Geography, 29(4), 505-515. https://doi. org/10.1191/0309132505ph564pr

Bowlby, S., Gregory, S., \& McKie, L. (1997).

"Doing home": Patriarchy, caring, and space. Women's Studies International Forum, 20(3), 343-350. https://doi. org/10.1016/S0277-5395(97)00018-6

Canada Mortgage and Housing Corporation. (2017, December 21). Applying a gender lens to housing in Canada: Perspectives on a gender-based approach to affordable housing in Canada. Retrieved from https:// eppdscrmssa01.blob.core.windows.net/ cmhcprodcontainer/sf/project/archive/ research_2/gender_lens_to_housing_in_ canada_.pdf.

Easthope, H. (2004). A place called home. Housing, Theory, and Society, $21(3)$, 128-138. https://doi. org/10.1080/14036090410021360

Frank, S. (2008). Gender trouble in paradise: Suburbia reconsidered. Research in Urban Sociology, 9, 127-148. https://doi. org/10.1016/S1047-0042(07)00006-2

Government of Alberta. (2012). Family violence hurts everyone: A framework to end family violence in Alberta. Retrieved from http://www.humanservices.alberta.ca/ documents/family-violence-hurts-everyone. $\mathrm{pdf}$

Hille, K. (1999). 'Gendered exclusions': Women's fear of violence and changing relations to space. Geografiska Annaler: Series B, 81 (2), 111 - 124. https://doi. org/10.1111/i.0435-3684.1999.00052.x

Klodawsky, F. (2006). Landscapes on the margins: Gender and homelessness in Canada. Gender, Place, and Culture, 13(4), 365-281. https://doi. org/10.1080/09663690600808478
Madigan, R. \& Munro, M. (1991). Gender, house and "home": Social meanings and domestic architecture in Britain. Journal of Architectural and Planning Research, 8(2), 116-132. https://www.jstor.org/ stable/43029027

Mallett, S. (2004). Understanding home: A critical review of the literature. The Sociological Review, 52(1), 62-89. https://doi.org/10.1111/j.1467954X.2004.00442.x

Meyer, S. (2016). Examining women's agency in managing intimate partner violence and the related risk of homelessness: The role of harm minimisation. Global Public Health, 11 (1-2), 198-210. https://doi.org/10.108 $0 / 17441692.2015 .1047390$

Rodrigue, S. (2016). Insights on Canadian society: Hidden homelessness in Canada. Statistics Canada. Retrieved from https:// www 150.statcan.gc.ca/n 1/pub/75006-x/2016001/article/14678-eng.htm

Shelton, K., Taylor, P., Bonner, A., \& van den Bree, M. (2009). Risk factors for homelessness: Evidence from a populationbased study. Psychiatric Services, 60(4), 465-472. https://doi.org/10.1176/appi. ps.60.4.465

Tognoli, J. (1980). Differences in women's and men's responses to domestic space. Sex Roles, 6(6), 833-842. https://doi. org/10.1007/BF00287238

Warrington, M. (2001). 'I must get out': The geographies of domestic violence. Transactions of the Institute of British Geographers, 26(3), 365-382. https:// doi.org/10.1111/1475-5661.00028

Wardhaugh, J. (1999). The unaccommodated woman: Home, homelessness, and identity. The Sociological Review, 47(1), 91 - 109. https://doi.org/10.1111/1467954X.00164 